\title{
Perforated Peptic Ulcer \& Its Association with Vascular Anatomy of Stomach \& Duodenum
}

\author{
Dr.Dharmendra Kumar ${ }^{1}$, Pratik Shahil ${ }^{2}$ \\ ${ }^{1}$ Associate Proffessor, Department of Anatomy, Rajendra Institute of Medical Sciences, Ranchi \\ ${ }^{2}$ Final year MBBS student, Kasturba Medical College, Mangalore
}

\begin{abstract}
Objective: To correlate clinical presentation of perforated peptic ulcer and the surgical approach used with the site of perforation.

Methods: This is a retrospective study conducted on diagnosed 52 patients of perforated peptic ulcer at the Department of surgery, Kasturba Medical College, Mangalore for a period of 1 year from January 2015 to December 2015

The details of all patients who were diagnosed and operated for PPU were retrieved retrospectively from medical record department and operation theater records. Case history and detailed clinical examination of patients were evaluated.

Conclusion: Site of the ulcer as reported by endoscopic assessment determines the clinical presentation and overall outconme of the patient.
\end{abstract}

\section{Introduction}

Peptic ulcer disease (PUD), is a break in the lining of the stomach, first part of the small intestine, or occasionally the lower esophagus. The most common symptoms of a duodenal ulcer are waking at night with upper abdominal pain or upper abdominal pain that improves with eating. With a gastric ulcer the pain may worsen with eating. ${ }^{[}$The pain is often described as a burning or dull ache. Other symptoms include belching, vomiting, weight loss, or poor appetite. About a third of older people have no symptoms. Complications may include bleeding, perforation, and blockage of the stomach. Bleeding occurs in as many as $15 \%$ of people..$^{[2]}$ Perforation is the commonest complication; emergency surgical intervention is always required to save life. Crisp's description of PPU in 1843, still stands true even today. Ulcer perforation was a lethal disease until surgical treatment was introduced at the turn of centaury. Mikulicz sutured a perforated gastric ulcer for the first time in 1880 and suture is still the most common treatment for ulcer perforation. The revolution in the ulcer treatment that occurred with the discovery of Helicobacter pylori has not yet led to any detectable changes in incidence of ulcer perforation

Based on the site of ulcer, the sequale of perforation can be assessed and a better emergency management could be planned.

Modified Johnson Classification

- Type I: Ulcer along the body of the stomach, most often along the lesser curve at incisura angularis along the locus minoris resistantiae. Not associated with acid hypersecretion.

- Type II: Ulcer in the body in combination with duodenal ulcers. Associated with acid oversecretion.

- Type III: In the pyloric channel within $3 \mathrm{~cm}$ of pylorus. Associated with acid oversecretion.

- Type IV: Proximal gastroesophageal ulcer

- Type V: Can occur throughout the stomach. Associated with the chronic use of NSAIDs

\section{Materials \& Methodology}

This is a retrospective study was conducted on diagnosed 52 patients of perforated peptic ulcer at the Department of surgery ,Kasturba Medical College, Mangalore for a period of 1 year. All patients were studied, who were diagnosed and operated for PPU. The details of patients who presented from January 2015 to December 2015 were retrieved retrospectively from medical record department and operation theater records. Case history and detailed clinical examination of patients were evaluated. Investigations viz. blood CBC, RBS, serum urea, creatinine, BT, CT, Electrolytes, HbsAg, HIV, urinalysis, ECG, X-ray chest P.A. view and X-ray flat plate abdomen in erect posture were carried out. USG was not a mandatory practice. Data were analysed using a questionnaire proforma, including patient's demographic details (age, sex), rural or urban, associated premorbid illness, previous history of PUD and faulty treatment, use of NSAID, cortisone and, alcohol use, smoking (bidi or cigarette) time between onset of symptoms and surgery, site of perforation, type of surgical procedure, postoperative complications and mortality. 
.The data were evaluated using SPSS 20. Mean \pm standard deviation were presented for numerical parameters and categorical variables were expressed as $\mathrm{n}(\%)$ on $95 \%$ confidence interval. No other statistical test was applied.

\section{Results}

Male predominance was seen in incidence of perforated peptic ulcer.40(76.9\%) patients were male and $12(23.0 \%)$ patients were female.

Table I: Sex distribution

\begin{tabular}{|l|l|l|}
\hline Sex & Number & Percentage \\
\hline Male & 40 & $76.9 \%$ \\
\hline Female & 12 & $23.0 \%$ \\
\hline
\end{tabular}

Most common clinical presentation was abdominal distension seen in 50 patients $(96.1 \%)$ and epigastric pain in 46 patients (88.4\%). 9 (17.3\%) patients presented with w severe shock, haemo dynamically unstable, with preexisting co morbidity, CRF and cardio pulmonary risks. . Overall mortality occurred in 4 patients $(7.6 \%)$. The common reasons were old age, co morbidity, late arrival and septic shock.

Table II: - Clinical presentation

\begin{tabular}{|l|l|l|}
\hline Symptoms & Number & Percentage \\
\hline Epigastric pain & 46 & $88.4 \%$ \\
\hline Vomiting & 40 & $76.9 \%$ \\
\hline Distension of abdomen & 50 & $96.1 \%$ \\
\hline Constipation & 27 & $51.9 \%$ \\
\hline Fever & 30 & $57.6 \%$ \\
\hline Shock & 9 & $17.3 \%$ \\
\hline Guarding, rigidity, rebound tenderness & 52 & $100 \%$ \\
\hline
\end{tabular}

Duodenal perforation was commonest $42(80.7 \%)$, prepyloric $3(5.7 \%)$ and gastric $7(13.4)$. Ulcer size ranged from $.05 \mathrm{~cm}$ to $2.5 \mathrm{~cm}$

Table III: Site of perforation

\begin{tabular}{|l|l|l|}
\hline Site of Perforation & Number & Percentage \\
\hline Duodenum & 42 & $80.7 \%$ \\
\hline Prepyloric & 3 & $5.7 \%$ \\
\hline Gastric & 7 & $13.4 \%$ \\
\hline
\end{tabular}

Simple closure of ulcer with omental patch, either free or pedicle graft (Graham' patch) was done in 30 patients (57.6\%).Laproscopic closure was done in 17 patients (32.7\%). Omental plugging was done in $3(5.8 \%)$ patients, in ulcers of more than $1 \mathrm{~cm}$. size. Simple abdominal drains were put in 2 patients $(3.9 \%)$

Table IV: Surgical approach

\begin{tabular}{|l|l|l|}
\hline Surgical approach used & Number & Percentage \\
\hline Simple closure with Graham patch & 30 & $57.6 \%$ \\
\hline Laproscopic surgery & 17 & $32.7 \%$ \\
\hline Omental plugging & 3 & $5.8 \%$ \\
\hline Simple abdominal drainage & 2 & $3.9 \%$ \\
\hline
\end{tabular}

\section{Discussion}

The clinical presentation, surgical approach to be used and prognosis widely depends on the site of perforation. Ulcers on the sites in the vicinity of major vessels of stomach predispose the patient of shock in case of perforation. Anterior duodenal ulcer perforates most commonly eroding the gastroduodenal artery , gastric ulcers on lesser curvature near the antrum perforate commonly,eroding the left gastric artery Massive bleed occurs when the ulcer erodes one of the blood vessels, such as the gastroduodenal artery or the splenic artery (in case of ulcers on posterior wall of stomach.. Perforation at the anterior surface of the stomach leads to acute peritonitis, initially chemical and later bacterial peritonitis. Posterior wall perforation leads to bleeding due to the involvement of gastroduodenal artery that lies posterior to the first part of the duodenum and occasionally the splenic artery, which may necessitate ligation of splenic vessels with splenectomy Duodenal perforation with small sized ulcer leads to dribbling of peritoneal irritatants from the site of perforation down the right iliac fossa through the right paracolic gutter, which leads to RIF pain (Valentino syndrome) Rarerly the perforated duodenal ulcer can be sealed by omentum leading to "dry perforation" 


\section{Conclusion}

Perforation of peptic ulcer is frequent surgical emergency and requires awareness and prompt management and operation. It mostly affects young and middle aged males. Endoscopic assessment of site of ulcer should be co related to expected clinical outcomes and Patient should be prescribed treatment for Helicobacter pylori and PPI. They should be advised to avoid the common risk factors like too much spicy food, smoking, excess alcohol use, and indiscriminate use of NSAIDs and should seek proper medical advice in time, and counselling them about alarming symptoms. Simple closure with omental patches i.e. omentpexy give excellent results

\section{References}

[1]. Crisp E. Cases of perforation of the stomach. Lancet. 1843;1:639.

[2]. Jennings D. Perforated peptic ulcer. Lancet. 1940;1:444.

[3]. DeBekay, M.: Acute perforated gastroduodenal ulceration. Surgery 8: 852, 1940

[4]. Svanes C, Lie RT, Kvåle G, Svanes K, Soreide O. Incidence of perforated ulcer in western Norway 1935-1990: cohort or period dependent time trends? Am J Epidemiol. 1995;141:836

[5]. Mikulicz J. Ueber Laparotomie bei Magen und Darmperforation. Samml Klin Vort Leipzig. 1885;262:2307.

[6]. Rauws EAJ, Tytgat GNJ. Cure of duodenal ulcer associated with eradication of Helicobacter pylori. Lancet. 1990;335:1233.

[7]. Elnagib E, Mcquaid E, Ahmed ME. Perforated peptic ulcer in Khartoum. Khartoum Med J. 2008;1(2):62-4.

[8]. Makela JT, Kivineum H, Ohtonen P, Latinen S. Factors that predveb morbidity and mortility in patieuts with perforated peptic Ulcer. Eur J Surg. 2002;168:446-51.

[9]. Mathur PN et al. Int Surg J. 2017 Jan;4(1):19-23

[10]. Turkdogan MK, Hekim H, Tuncer I, Aksoy H. The epidemiological and endoscopic aspects of peptic ulcer disease in Van region. Eastern J Med. 1999;4(1):6-9.

[11]. Svanes C. Trends in perforated peptic ulcer: incidence, etiology, treatment and prognosis. World J Surg. 2000;24(3):277-83.

[12]. Chaliya PL, Mabula JB, Koy M, Mchembe MD, Jaka HM, Kabangila R, et al. Clinical profile and outcome of surgical treatment of perforated peptic ulcers in north western tanzania: a tertiary experience. World J Emergency Surg. 2011:6-31 